Christos A. Zafiropoulos

University of Patras czaf@otenet.gr

\title{
AHIQAR, HIS TALE AND THE VITA AESOPI
}

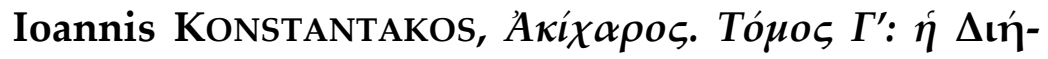

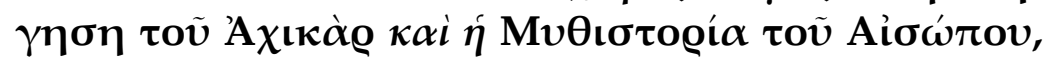
Athens, Stigmi, 2013, 616 p. ISBN 978-960-269-250-9
\end{abstract}

This is the conclusion of a three-volume study on the Near-Eastern Tale of Ahiqar and its Greek reception by Ioannis Konstantakos, Assistant Professor of Classics at the University of Athens. As its title suggests, the final volume addresses the relation of Ahiqar to the Vita Aesopi, a novel-like narrative on the life, the adventures and the death of the legendary euretes of Greek fable, which was composed sometime between the first century B.C. and the second century A.D. Konstantakos focuses on a particular aspect of Ahiqar's literary and cultural reception, its use as the matrix upon which the so-called "Babylonian section" of the Vita Aesopi was modeled.

The whole study is a Herculean task, a voluminous work of approximately 1360 densely printed pages in total, with many inserted digressional discussions on particular subjects in much smaller fonts, which constitute in their own right separable and outstanding essays. To aid the reader, the third volume is preceded by translations of the main texts that K. shall compare, the Aramaic version of Ahiqar that survives in a fifth century B.C. papyrus from Elephantine in Egypt (based on Bezalel Porten's and Ada Yardeni's 1993 edition of the text), the Syrian recension of Ahiqar (following Frederick Conybeare's, James Rendel Harris' and Agnes Smith Lewis' text) and the Babylonian section of the Vita in K.'s translation, an accurate, refreshing and flowing one, although a few of its selections might puzzle the non-native Greek speaker (such as the idiomatic expression " $\tau \dot{\alpha}$

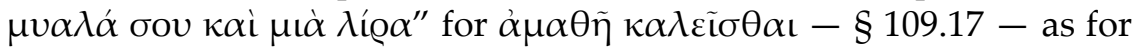
the text, K. mostly follows Franco Ferrari's edition).

In the introductory chapter K. provides a condensed, yet particularly profound overview of the state and the textual tradition of the 
Vita (1.1). The surviving redactions and papyrus fragments suggest a tradition that was quite rich in late antiquity. K. sides with most scholars and he too considers the G redaction (the 'Grottaferrata' or 'Perriana') as the oldest full version that we possess and the one that is most representative in form and content of the now lost archetype, which was composed some time between the first century B.C. and the second century A.D. Accordingly, it is this redaction that he resorts to for his comparative study of the Babylonian section (G 101$123)$, i. e. the episodes that narrate Aesop's adventures and intellectual triumph in Babylon and in Egypt. He also rejects, with good arguments and in agreement with most scholars, alternative suggestions on the original composition of the Vita as early as the fifth century B.C. or in the Hellenistic period (pp. 62-64, cf. pp. 78-82). As for the provenance of its author $\mathrm{K}$. examines the various hypotheses (an Egyptian according to Ben Edwin Perry, a Syrian, following Antonio La Penna) to conclude that no definite answer can be put forward yet, although his study clearly points (as in 4.2, cf. pp. 553-554) to the author's special knowledge and interest in Egyptian culture, especially under Roman rule. K. proves that he was a well-educated man and a connoisseur of Greek literature, particularly so with respect to popular narratives, didactic and gnomic literature and material on renowned Greek intellectuals.

As for the reception of Ahiqar in Greece, a good part of the first volume and the whole second volume of Aкix $\alpha \rho \circ$ s have already provided the reader with a detailed study on the matter (especially the second volume, e. g. on Democritus' supposed translation of Ahiqar and on the Peripatetics' special interest for that text and Theophrastus' Ahiqar) and on the place in Greek culture and literature of specific themes in the Ahiqar narrative (like the building of imposing constructions up in the air, riddle contests and stories on the original unrighteous disfavour and the ensuing restoration of a sage's fame and status in a royal court). This volume culminates K.'s study on the textual field, with an exhaustive philological, comparative reading of the Babylonian section and the extant redactions of Ahiqar. K.'s reading also opts for stylistic, aesthetic, ideological and other differentiations of the Vita from Ahiqar that point to its author's tactics and predilections in his integration of his oriental model. Thus they draw his artistic identity and reveal the essence of his art, which in turn shall facilitate the future study of the Vita. This point of view in K.'s research might argue for his constant labeling of that particular com- 
poser of the original Vita as the 'Author'. On the basis of his overall view of this Author as an erudite and most competent writer (see esp. pp. 541-552), one may consider this labeling as a subtle statement of K.'s alignment to many scholars' appreciation of this author's mastery in handling his material (a judgment to which we too subscribe, especially on the basis of the ideological congruity of the Vita).

$\mathrm{K}$. then discusses in extenso the many similarities and analogies between the literary figures of Ahiqar and Aesop, which most probably generated and sustained the amalgamation of their traditions in the Vita (1.2). K. notes the affinity in the generic armament that both protagonists employ in their similarly didactic, admonitory and censorious roles. They both act as political counselors and as moral instructors and educators via the narration of simple, brief and popular didactic and gnomic utterances and they use similar techniques to answer and excel in riddle solving. Likewise, they are both the innocent victims of human mischief and treachery, yet in the end truth and justice do prevail and both Ahiqar and Aesop are vindicated. K. asks who was the originator of their correlation (1.3) and he argues that it is plausible (and supported by his research) that this was he work of the Peripatetics. Additionally, K. argues (pp. 74-80) for a similar appropriation by the Author and for the prolific incorporation in his narrative of biographical material on other eminent Greek intellectuals, such as Diogenes of Sinope, Socrates and the Seven Sages.

It is under these programmatic interpretative lines that $\mathrm{K}$. begins

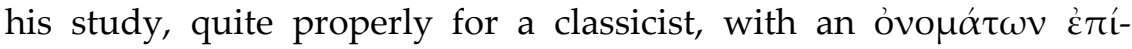
$\sigma \kappa \varepsilon \psi ı \varsigma$ on the protagonists of the Babylonian section. With the exception of Aesop, whose name the Author could not alter given he was already his protagonist, $K$. evidences that all the other names were his deliberate options in line with his narrative and ideological premises. The greatest part of this chapter is devoted to the two monarchs involved, Pharaoh Nectanebo (2.1) and the Babylonian King Lykoros (2.2). As regards the former, his name marks a paradoxical and puzzling anachronism by the Author, given his preference for accuracy and verisimilitude: in place of the Pharaoh's anonymity in Ahiqar, he opted for a historical monarch, though one who actually reigned two centuries after Aesop. He could have chosen Amasis, who would have provided most suitable choice because of his contemporary reign to Aesop's acme. To explain the Author's choice K. proceeds to an in depth discussion of episodes and attributes of Nectanebo from a set of narratives on him that the Author might have been familiar 
with. These sources (pseudo-Callisthenes' Alexander Romance 1.1-12, The Dream of Nectanebo, the Demotic Chronicle, Diodorus Siculus 16.4748 and 51 and The Praise of Imouthes) testify to specific (mostly negative) characteristics of Nectanebo's literary portrait that matched the traits and the behaviour of the anonymous Pharaoh in Ahiqar and thus suited and justified the Author's choice. Nectanebo was stereotyped as the archetypal Egyptian Pharaoh, who once challenged and declared war on a great power from the Orient, but lost it and set his people under foreign control. He was considered as a crafty man (yet also one who fatally overestimated his power) who resorted to magic and trickery, but also as a notoriously greedy and avaricious ruler, the last two being most characteristic traits of the Pharaoh's character in the Vita that K.'s ably tracks and stresses.

Similarly, as regards the Babylonian King, the Author opted for details that served his narrative purposes and strengthened the thematic cohesion of his work. That is, he replaced the historical Assyrian kings of the Ahiqar versions, Sennacherib or/and his son Esarhad-

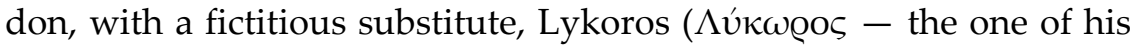

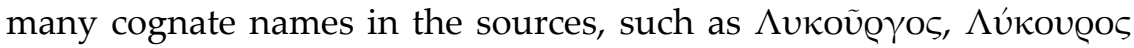

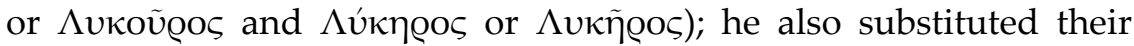
capital, Nineveh, with Babylon. K. explains the former choice on mythological and thematic grounds, for it recalled a mythical hero of the same name, Apollo's son, who was strongly connected with Delphi and its neighbouring area, let alone that it evoked cognate epithets of the Delphic god. Thus, the King was implicitly and masterfully linked to Apollo and, accordingly, the theme of his erroneous enmity with Aesop and his order for the sage's death was consolidated with the most pivotal theme of the Vita, the god's conflict with the hero (at the same time these apollonian connotations also preface the transfer of action at Delphi).

In the case of Hermippos (2.3), the military officer who disobeys the King's erroneous order to execute Aesop, hides him instead and thus becomes his saviour, K. argues that the Author kept his office and role in the plot from the oriental model, but he also changed his name in the Elephantine text, Nabusumiskun, a common Akkadian name for officers, into its Greek etymological equivalent that also suited the theological-ideological premises of the Vita. He conveyed Nabusumiskun ("god Nabû procreated an offspring") with a Greek compound that suggested a connection with Hermes. K. notes, however, that the most appropriate candidate in cultic and literary terms 
should have been Apollo. And he explains Hermes' choice on the thematic consistency of the Vita, in that an 'apollonian' name for Aesop's saviour would contradict the recurrent theme of the enmity between Aesop and Apollo. In addition, K. cites a series of analogies of the attributes and the sphere of functions between Nabû and Hermes which argue for the Author's special knowledge of the Mesopotamian pantheon.

As for the name of Aesop's adoptive son (2.4 - the chapter ends with the deletion of Ahiqar's wife from the Vita, 2.5), once again the Author changed it for reasons of narrative orderliness. In the Vita Aesop is an outsider to Babylon (and overall he is emphatically deprived of family ties or of close social bonds, contrary to the importance of the oikos in Greek novels - perhaps not a surprising choice for a slave). So the Author turned Ahiqar's nephew into a local young nobleman (thus, however, creating a class contrast with the freedman). K. proceeds into a careful hermeneutical and narratological examination of the three names that the sources provide for him, "H $\mathrm{H} \lambda$ เos (in the G), Aĩvos (in the Westermanniana version - W) and $\Lambda \tilde{i v o s}$ (codex Vindobonensis theol. Gr. 128). Linos was a mythological figure with many potential connotations with the antiapollonian theme of the Vita (for example, he is a punished music contestant of Apollo, reminiscent of Marsyas to whom the Author refers in G 100). Yet, the correct form should have been $\Lambda$ ivos, without a circumflex, so $\mathrm{K}$. rejects $\Lambda \tilde{i}$ os as the original name and explains it as a corruption from Aĩvos. Furthermore, Linos' mythological persona would contradict his behaviour to Aesop (he falsely accuses him of treason), that of someone who should rather be in the "apollonian camp." Instead, K. opts for "H $\lambda \iota \mathrm{\iota}$, because of its apollonian semantics and of the many solar-apollonian allusions in the Babylonian section by which the Author constantly depicts and escalates the conflict between his protagonist and Apollo.

Nevertheless, in our view Aĩvo should be reconsidered as a more suitable candidate, under the same notional and narrative criteria that K. adopts in his research. As he too states, aivo the sources as the archaic Greek term for 'fable', therefore, it would be a most appropriate name for Aesop's son, especially so, given the Greek practice that $\mathrm{K}$. describes, of naming the son after an activity or

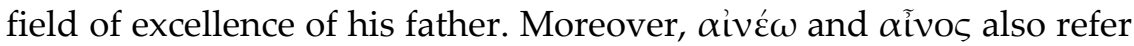
to admonitory discourse and in this respect Aĩvo would hint at the son's agoge by means of exhortatory precepts. Nevertheless, reading 
$\alpha$ ĩvos against the bipolar background of the apollonian/anti-Aesop versus the aesopic/anti-Apollo, K. concludes that the ainos, Aesop's property par excellence and his (divinely granted) beneficial armament in the Vita, could not feature in the name of a person who turns against the fabulist. Yet, from a different perspective, the candidacy of Aĩvos would gain further support. That is, an alternative point of view may as well be that of the benefits that the ainos holds, not for its pronouncer, but for its recipients. Aesop the fabulist, the "benefactor

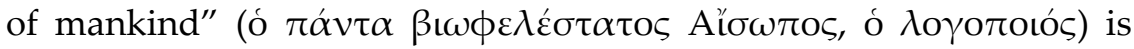
thus marked from the very first words of the Vita (G 1, with an almost identical phrasing in W 1). Suggestively, his life and adventures deserve to be studied not because of the benefits that his logoi, among which the ainos, brought upon him, but rather because of their educative benefaction upon their (and the Vita's) readership. Their utility regards and depends upon the perceptive and cognitive abilities of their recipients and the application by them of their messages. In this respect, the ineffectiveness of the adoptive son's agoge may be seen as an illustrative case-study of the recipient's participation and responsibility in the didactic process and function of Aesop's logoi. They were not beneficiary to him (or perhaps they are, see the discussion of his death below) exactly because, contrary to the Samians or King Croesus, or even the vacuous Xanthos, the adoptive son fails or refuses to understand and adhere to their message. In addition, the name Ainos is also functional structurally, for it seems to introduce the gradual fading of the persuasiveness and the didactic benefits of Aesop's discursive means, which shall culminate in the dysfunction of his fables against the Delphians. Besides, the usual meaning of aĩvos, already in Homer, was "spoken words with a hidden meaning" that called for decipherment by its recipient (see G.-J. Van Dijk's Ainoi, logoi, muthoi, Leiden 1997, 79-80). Accordingly, the adoptive son's name, the whole episode of his failed agoge and the reproaching maxims that Aesop utters at him would indicate that the educational process, if not close human relations in general, is actually a kind of riddle the hidden message of which falls to the educated to solve and then to apply it in his life. Contrary to Ahiqar and Aesop, champions in riddle-solving, Ainos proves to be incapable of answering the aĩvo of his agoge and he pays the price for it. From the opposite route, the Delphians shall soon reach the same outcome. They do decode the (defamatory and threatening) meaning of the aetiological fable that Aesop delivers against them (G 126-127), but they will de- 
ny to apply its message and change their attitude and in the end they too pay a heavy price.

Chapters three and four form the core of the book. They constitute an impressive philological tour de force on the many different ancient literary traditions and cultures that participate in the traditions of Ahiqar and the Vita, so rich and detailed that it cannot be reproduced in the limits of a review. The third chapter discusses the riddle contest between the sage (Ahiqar/Aesop) and the Pharaoh and his counsellors, which the Author designedly turned into the lengthiest part of the Babylonian section (G 105-108, 111-123 - the reader may find it useful to consult here the second part of the first volume of K.'s study, on riddle contests). The utterance of riddles by Aesop and his excellence in their agonistic solving are motifs that permeate the Vita, cohere it and reach their apogee in this section (3.1.1, 3.1.4). K. compares the riddle contests in the Vita and in the different versions of Ahiqar and he scrupulously reveals the Author's composing tactics, his interferences in the narrative (mostly by condensing or curtailing the various episodes $-3.1 .2-3$, but also inserting additions to it to safeguard its cogency - 3.2). He also argues that as regards the number and the sequence of the riddles the Ahiqar tradition was quite open, whereas the Author possibly drew the order of the Vita riddles from the original version of Ahiqar (3.3). With respect to the deviations of the Vita riddles from its model, K. notes the omission by the Author of two adynata (challenges that are seemingly impossible to answer) that were set to Ahiqar, to knit a rope made of sand and to sew a broken millstone (3.4). He explains their exclusion on their absence from the version of Ahiqar that the Author used.

$K$. then analyzes at length the literary and cultural traditions behind the different formulations of the two adynata that the Author retained in the Vita and he interprets their divergences from their presence Ahiqar (such as in their phrasing or imagery). Aesop is challenged first with the adynaton of building a castle that would touch neither the heaven nor the earth (3.6 - the Author changed its formulation in order to recall a Greek proverb) and then with the paradoxical miscarriages of the Pharaoh's mares whenever they hear the horses of Lykoros neigh from far away, from Nineveh (3.7). K. also surveys the cross-cultural traditions and the deviations of the Vita with respect to the "simile riddles," the different allegorical spectacles that the Pharaoh and his entourage stage and Aesop must decode (3.5). K. notes the highly rhetorical and embellished style of Aesop's 
illustrations (3.5.5) and carries out a set of illuminating remarks on the Author's selections and adaptations of the oriental divinities that featured in the oriental versions (3.5.2, 3.5.6.2, 3.5.7). As for the remaining content of the contest, Aesop is asked to decipher the allegorical meaning of the enigma of the year and its subdivisions (3.8), the imagery of which differs strongly in the Vita (a temple - i. e. the oikoumene - contains a pillar, the year, that houses on its top twelve cities, the months, and so on); there is also the tricky challenge to report something that neither the Pharaoh nor his courtiers have ever heard or seen (3.9 - the Vita seems to reflect the original form of the utterance). In the end, after Aesop wins the contest, $\mathrm{K}$. sheds light upon a detail that is quite revealing of the Author's skills and narrative tactics: his calculated depreciation of Nectanebo is reflected in the inconsistency between the agreed material rewards for the winner and the cost that the Pharaoh actually pays, which is considerably smaller, thus pointing at his stinginess and his pettiness (3.10).

The fourth chapter focuses on the Author's ideological, aesthetic and narrative incentives and on the related divergences of his work from the oriental original. Most characteristically, he persistently eliminated or altered those behavioural traits of Ahiqar that might run against the cultural requirements and the ethical premises of his Greek readership. Ahiqar's vengeful rage at his nephew, his rampant physical and verbal violence against him, his pitiless deafness at his pleas and his sarcastic comments over his dead body were erased from the Vita narrative, or they were toned down (4.1.1). The Author deliberately depicts his protagonist as a gentle and caring sage, mild and didactic in his censure, a forgiving and magnanimous man, who is thus closer to a Greek humanitarian perception of social interaction. For example, in Ahiqar it is actually a slave who is deceptively executed in place of the sage. Although this scheme would have recalled the motif of the protagonist's fake death in many Greek novels, the Author removed the ploy with the innocent surrogate victim and thus he rendered the plot more humane and cleansed his protagonist from any blame for such an act (4.1.2-3 - let alone the ideological inappropriateness of Aesop the freedman surviving at the expense of a slave).

The Author also made a set of changes on particular narrative details regarding Egypt so that he would clarify the vagueness of Ahiqar at certain points. Hence he served his taste for realism and accuracy and added a couleur locale (4.2). These include the setting of the Egyp- 
tian episodes in the capital Memphis (4.2.2), Aesop's travelling there not by land, but by ship (a more justifiable option from a Greek's point of view, 4.2.3), details from Egyptian religious iconography together with local customs and beliefs (4.2.4-6), the addition in the plot of the priests from Heliopolis who have a leading role in the riddle contest at the side of the Pharaoh (4.2.7-8). Those particular priests were highly esteemed as emblematic representatives of Egyptian wisdom, most respected by the Greeks. Their presence in the Vita further testifies to the Author's knowledge of Egyptian culture and religion, even more so given that he uses the word $\pi \varrho 0 \phi \tilde{\eta} \tau \alpha \iota$ to denote them, a special term that was used from the Ptolemaic era onwards for the higher hieratic hierarchy (but a term that also calls to mind the human revealers of Apollo's will and thus enlists the Heliopolis priests in the conflict motif - 4.2.7-8). His special knowledge of Egyptian political institutions and terminology is also testified for the Pharaoh's councils and their meetings (4.2.9-10). K. answers the resulting question if all these details point to the Author's Egyptian origins by pointing out that they were rather widespread knowledge and present in many local narratives that the Author was acquainted with and could have drawn this information from there. Accordingly, no definite conclusions can be drawn on his origins, although he must have spent some time in Egypt and perhaps his intended readership included certain learned locals (4.2.11).

K.'s research then moves to the Author's tactics of inserting and repeating themes in order to secure the cohesion of his work, the most preeminent being Aesop's conflict with Apollo. Additionally, there are the sage's hidings and their correspondence to his later imprisonment at Delphi (4.3.2), the banquet with the Heliopolis priests which continues the theme of Aesop's excellence in wisdom at sympotic contexts (4.3.3), the epistolary correspondence of the two monarchs (4.3.4-5), Lykoros' order to honour Aesop by erecting a golden statue of him among those of the Muses (G 123) which responds thematically to Aesop's similar honours in Samos. These were disrespectful of the 'Musagetes' god, the leader of the Muses and rightful head in any depictions of their chorus ( $G 100-4.3 .6)$ and thus they caused his anger at the fabulist and triggered their conflict (cf. W 142, where the Delphians erect a temple and a stele to expiate themselves for Aesop's murder). Other intentional variances from Ahiqar resulted from the Author's adjustment of his protagonist's portrait in the Babylonian section to his traits in the rest of the work, 
as regards both his aesthetic and his social properties. For example, he expunged Ahiqar's family ties (his nephew, his wife) in order to be in line with the social vacuum that characterized the fabulist's personal life and his old age (4.4.2 - K. takes Aesop to be in his prime, yet the Vita provides no clear indications on that aspect of the protagonist). Besides, he inserted brief references to the recurring theme of Aesop's monstrous deformity (4.4.3), whereas he similarly turned the servile oriental sage into a dignified, liberal and outspoken spirit (4.4.4). One, however, should keep in mind that in the Vita as a whole Aesop is not a radical or even a liberal voice; instead, his ethics and actions are rather utilitarian and aspire to guarantee his personal survival and to ameliorate his condition.

$K$. further distinguishes certain variations that cannot be grouped into broader categories and be analyzed accordingly (chapter 5). Contrary to the aforementioned differences from Ahiqar, these do not pervade the Babylonian section or constitute distinctive features of the Author's stylistic or ideological options. Thereof it is difficult to trace their origin in the tradition of the text. To cite a few examples, compared to Ahiqar, the Vita is significantly vague and brief with respect to the material rewards by Lykoros to his officer for having saved Aesop (5.2.1.1-2). K. considers this to be another case of the Author's curtailing intervention in line with his narrative economics, namely to reduce the episodes that preceded the riddle contest in order to augment the latter. Regarding Hermippos' rewards in status, Lykoros awards him the title of $\sigma \omega \tau \eta \dot{Q}$. K. discusses Corinne Jouanno's suggestion that the word corresponds to a formal term from the

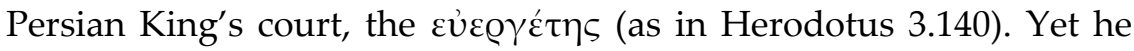
adds a tempting hypothesis, i. e. that it also recalls a particular royal agnomen of Hellenistic monarchies, famously recorded for Ptolemy I (o $\Sigma \omega \tau \eta \dot{~} \varrho$ - 5.2.1.3). Similarly, instead of the various titles that the Pharaoh's and the King's attendants hold in the versions of the Ahiqar, the Vita opts for specific terms from the Greek terminology for

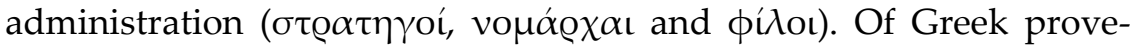
nance are also the properties of $\gamma \varepsilon v v \alpha i ̃ o s$ and $\mu \alpha \dot{\alpha} \chi \mu о \varsigma$ that Aesop uses to describe the King's rooster (G 118), thus reproducing the most acclaimed attributes of the animal in Greek cock-fighting (5.2.6). On the other hand, the statement at G 116 that the Babylonian King has

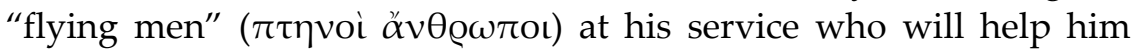
build a castle in the sky, might refer to the winged demons in human form that are depicted in Mesopotamian art, for which $\mathrm{K}$. presents a 
detailed account (5.2.4). Finally, there are certain exclusivities of the plot of the Vita the origin of which cannot be determined. For all these, K. presents a detailed and careful comparative reading of the two narratives in their various versions. They include the motives behind the adoptive son's betrayal of the sage and his adultery with one of the King's concubines (5.3.1-2), the sentimental reactions of the two monarchs, namely the absence from the Vita of any reference to the Pharaoh's joy at the news of the sage's death (5.4) and the differences in the description of the King's mournful despair at the loss of Aesop (5.5), as well as differences in the description of Aesop's departure to Egypt (5.6).

In the last chapter $\mathrm{K}$. compares the sayings that Aesop addresses to his adoptive son in the Vita (with respect to their number, their place in the narrative, their kind, form and content) to the maxims that Ahiqar utters to his nephew in the various redactions of Ahiqar. The latter generally include two groups of maxims. The first consists of precepts and admonitions on the proper conduct in various forms of social relation and interaction and it is part of Nadin's education by the sage. The second group is chiefly composed of brief parables or fables that constitute Ahiqar's indictment against his ingrate and treacherous nephew, a severe verbal castigation that seems to complement the nephew's physical torture with the torturing of his soul. Actually, it can be argued that it was this very moral punishment that generated his horrible death (he was inflated like a sack - 6.1.1) With respect to a broadly uniform tradition, the earliest surviving text of the Ahiqar contains only a single set of sayings, of varied generic and ideological classification, with no retributive content or any indicated connection to the plot. They seem, in both form and content, like an appendix to the plot of the Elephantine text, which resembles a diptych consisting of a narrative and a gnomic part. On the other hand, the Vita contains a single set of precepts, placed at the point of the son's moral reformation by Aesop. But there is no retributive tone or content here, no moral punishment in connection to his previous slips (6.1.2). Once again, K. sets off to a meticulous presentation of scholars' suggestions on this incongruity, then to their critique and finally presents his own interpretation (6.1.3). His hypothesis is that the redaction of Ahiqar that served as a model for the Author of the Vita was in line with the bulk of the tradition, that is, it included two different and separate sets of sayings which the Author himself then condensed into a single set. He also replaced the severe verbal re- 
proof of the second set of the Ahiqar recensions with aretological ethics that recalled their first set of admonitory sayings. In textual support of his thesis, K. cites a passing note in G 109: Aesop asks his adoptive son to listen to his words, by means of which he had been educated in the past, yet he did not reciprocate that gratitude

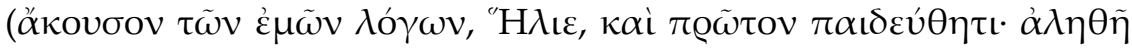
$\dot{\varepsilon} \mu$ oì $\tau \dot{\alpha} \varsigma \chi \alpha \dot{\alpha} \varrho \iota \tau \alpha \varsigma \dot{\alpha} \pi \hat{\varepsilon} \delta \omega \kappa \alpha \varsigma)$. This passage indeed testifies to K.'s thesis; it indicates a reference to the first set of educative sayings that were uttered during the young man's agoge by the sage which the Author mingled with the second set (6.1.4).

The omission from the Vita of the verbal violence of the second set of parables is persuasively explained by $\mathrm{K}$. as a conscious choice by the Author which resulted from a combination of his ethical standpoint with the economics of his narrative (6.1.5). The moral factor was again the Author's 'humanization' of the oriental archetype, the turning of the revengeful and physically and verbally violent Ahiqar into the mild, moderate and magnanimous Aesop, thus reproducing the Greek belief in the educating power of human logos. In addition, the Author did not want to overload his narrative at this point with fable-like admonitions like those that Ahiqar narrated during the castigation of his nephew, because he intended to use fables in the following Delphic section of the Vita, where Aesop resorts to his distinctive genre in order to vituperate the Delphians for their behaviour, in a use of $p$ sogos that is reminiscent of iambic or Old Comedy discourse.

Still, this episode calls for further discussion. As K. himself admits, the set of precepts that resulted from the Author's intervention was too moderate and mild to have caused the son's ensuing self-imposed death by abstinence from food. And an argument that such inconsistency with the following events was the price that the Author had to pay in order to keep the culprit's death yet minimize his protagonist's violent part in it (p. 491) is not worthy of K.'s thorough and penetrating analysis throughout his study. In our view, an alternative interpretation might be at place here, one that would reestablish the Author's masterful handling of his material. From the many scholar interpretations that K. discusses (pp. 492-495), one in particular should call for further investigation. Maria Jagoda Luzzatto has emphasized the educative and philosophical content of these precepts and she argued that through these the Author wanted to underline the power and the effectiveness of Greek paideia that is articulated on the basis of reasoning. Accordingly, contrary to the failure of Ahi- 
qar's maxims and education of his nephew, the Greek adaptation highlighted the internalization of logos, the seeds that the precepts planted in the agent's soul which touched upon his consciousness and turned into remorse. Although $\mathrm{K}$. aligns with this approach, he does not pursue it further on the grounds that Luzzatto traces the origins of these precepts in the Greek gnomic tradition, whereas he, rightly, counter-proposes the Author's appropriation of the Ahiqar material. Nevertheless, another interpretative path might prove to be fruitful first if one slightly transposes Luzzatto's emphasis from the generic and the philosophical to a broader examination of the sage's logos in the Vita, as regards its internalization process by the agent (in line with the importance of reasoning and argumentation in Greek culture) and chastising power (in line with the traditional power of psogos); in addition, this examination should address the effectiveness of Aesop's discursive means in their cognitive and contemplative function throughout the Vita.

In this regard, we point that the episode with Aesop uttering his precepts and their ensuing consequences mark a climax in relation to the preceding episodes. That is, throughout the introductory and the Samian part (Aesop's servitude in Samos) we witness Aesop's reasoning, often in defense of truth and justice, but also the reactions of the unjust or the erroneous (ethically or as regards argumentation), both being recipients of his criticism, reproach or witty remarks. The Author often applies cognitive verbs, such as $\gamma \iota \gamma \nu \omega \omega \kappa \omega \omega$ or oîd $\alpha$, or the narrative suggests, without specific verbal markers, that they are conscious of their actions, that they ' $\mathrm{know}^{\prime}$ or that they 'perceive' the truth, despite failing to accept it or to correct themselves. It is often stated that they 'learned' their lesson or they admit their defeat by Aesop in argumentation or in wit (e. g., G 2-3, 9, 19 and most of the exchanges in the Samian section between Aesop and his master, Xanthos, a parodied intellectual). As the plot progresses, Aesop's discourse becomes more understood, accepted and rewarded: the Samians apprehend and adopt the intended meaning of his fables

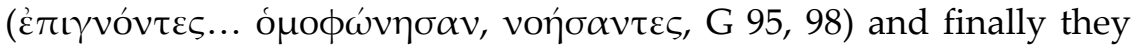
honour him (G 100), whereas Croesus similarly appreciates and rewards Aesop's intelligence and his logos (G 100). As we enter the Babylonian section, we read that king Lykoros too valued Aesop (G 101), until he fell for the adoptive son's false accusations of the sage (G 104). The power of Aesop's logos reaches its apex in the fatal exchange that he has with the culprit. Just before he delivers his pre- 
cepts it is clearly stated that he set up to admonish him with his logoi

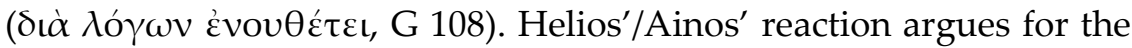
reflective and internalized effectiveness of these admonitions: he was saddened for his injustice against Aesop and at his sayings ( $\lambda v \pi$ oú-

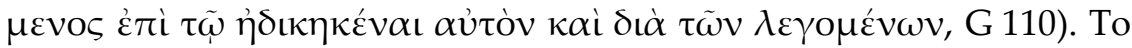
his reaction we may juxtapose the Delphic officials' later comprehension of Aesop's derogatory fable against them (he aetiologically descends them from former slaves of common ownership by all the Greeks), yet when they reflect upon his words they do not consent to

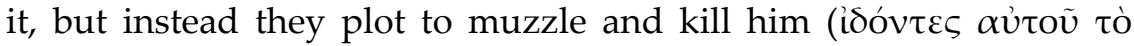

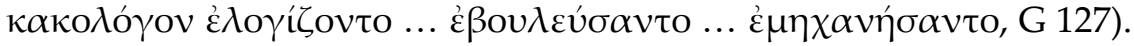
Hence, the power and the persuasiveness of Aesop's logoi shall dwindle (in the end he shall be totally unable to dissuade his executors), their internalization by his audience will work against him and (ostensibly) there is impunity for those who wrong him.

Future research may as well address the Author's choices at G 110 alongside these lines. As for the provenance of the precepts, $\mathrm{K}$. first distinguishes the four relevant sources (6.2.1), the $G$ and $W$ recensions, as well as the sayings in the codex Vindobonensis theol. Gr. 128 and in the P.Oxy. 3720 (our earliest source that dates in the third century A.D. and therefore it is quite close to the original Vita). He considers the latter to provide our best source and it is on its basis (alongside with the Vindobonensis) that K. completes his study with an exhaustive comparative reading of the maxims in Ahiqar to a set of 26 precepts from P.Oxy. 3720, together with their versions in the other sources (pp. 502-533 - 6.2.3). Scholars agree that only a few of the sayings in the Vita stemmed from those in the Ahiqar redactions, only two to four at maximum. Most are thought to be additions by the Author who derived them from various Greek gnomic sources, such as the maxims of the Seven Sages, admonitory utterances attributed to Socrates, Delphic precepts and other such material. Against this suggestion, $\mathrm{K}$. readdresses and actually grounds on a detailed textual analysis Norbert Oettinger's thesis that the sayings in the Vita and in Ahiqar share a thematic relevance, although often the former's themes and ideological content have been 'de-orientalized'. In most cases the Author modified them to suit the requirements and particularities of Greek ethics and culture, or he revised and adjusted others in order to match the plot and the ideas of his novel or the form of his protagonist, or to imitate popular Greek sayings and thus sound more familiar to his readership $(6.2 .2,6.2 .4)$. In our view, K.'s argument 
should involve a more elaborate reading of the maxims in the Vita in comparison to its overall ideology and to the conduct that characterizes its protagonist. K. occasionally attempts such a reading, but he does not do so systematically. That is, research should also address if and to what extent Aesop himself practices the messages of the admonitions that he utters to his adoptive nephew. One should examine then whether these precepts constitute the ethics of the Vita or if, instead, they are imported replicas of their oriental prototypes, easily incorporated into the Greek text because of the commonality of their messages in the normative popular ethics of many cultures, including the Greek. In our view, most of these precepts are compatible with Aesop's own conduct in the Vita and with the moral lessons to be drawn from his adventures and his logoi.

For example, as the precepts demand, Aesop himself is a living example of piety and respect to the divine (yet not to Apollo), he proves his loyalty and respect to the king and he has learned to avoid the wicked ones and their envy. A former slave, he is conscious of the importance of covering one's daily needs for food and that a dog should wag its tail in order to feed itself (cf. fables 91 in Perry's Aesopica and 100 in Babrius - 346 in Perry, it is rather tempting here

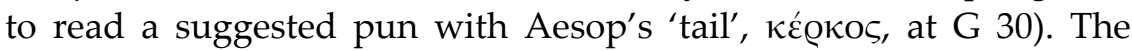
same goes for the admonition on keeping a low profile; Aesop learns that lesson by often being punished for his meddlesomeness and for his unbridled mouth. Aesop is a paradigm of prudence and temperance, but also a good example of both revenge and forgiveness upon those who have mistreated him. On the other hand, his portrait in the Vita sets him apart from those precepts that discuss the proper conduct to one's parents and wife. Socially and politically, Aesop is the counter-example of a Greek man: he is not bound to a polis, to parents, to a family of his own. In conclusion, from the perspective of the overall ethics of the Vita, it can be argued, in agreement with K.'s judgment, that actually the similarities between the two traditions as regards their collections of sayings support a relation of dependence between them. The maxims in G 109-110 must have derived, in total, from some group of admonitory utterances that were contained in a version of Ahiqar, possibly the model version that the Author had at his disposal and used (p. $534-6.2 .4$ ).

Furthermore, their thematic liaisons with the rest of the text hint at the Author's overseeing and full mastery of his material, thus supporting K.'s overall argument that in fact he was a rather skilful au- 
thor who carefully planned and safeguarded the narrative, aesthetic and ideological economy of his work, not just a compiler of traditional, ready material. In fact, K.'s work reinstates, enriches and strengthens Niklas Holzberg's thesis on a competent, erudite and artful author who masterfully and harmoniously incorporated in his narrative not only Ahiqar's adventures, but also a whole set of biographicalanecdotological material on some of the most eminent figures from the Greek intellectual tradition, such as the Seven Sages, Socrates or Diogenes of Sinope. These cross-generic narrative loans and his many other interventions that we discussed substantiate that the Author of the original Vita did not intend his work to be an 'open text', with a rather 'fluid' narrative that was meant to be subject to future variations and alterations (pp. 541-548).

The following extensive bibliography and the indices of names, works and passages and themes are particularly useful, especially so since $\mathrm{K}$. has provided a reference work on the subject. He has mastered a comprehensive comparative study that is both impressive and exemplary as regards the width and the copiousness of its literary and cultural subject matter, but also with respect to the acuteness of its philological scrutiny. Some of its shortcomings are perhaps inevitable in such a lengthy discussion, such as repetitions of issues or the occasional dispersion of the material under consideration (e. g. duplications of arguments at the concluding parts of each chapter and the dispersed sun-connotations at pp. 143-144 and 324-336). Apart from these, the points that this review has raised are not shortcomings of K.'s argumentation per se, but they result from the expectations for further analysis that it raises. From these we would single out the reading of the Author's ideological preferences with respect to the Vita as a whole and the examination of the precepts' content with regard to the plot and Aesop's conduct in the Vita.

Konstantakos ends his book with the following remark: "the comparative study of the Vita and Ahiqar ultimately provides us with an opportunity that is rather rare for ancient texts. Namely, it lets us have a peek, and a good one, into the very workshop of the author of the Greek narrative" (p. 557). However, the same can also be argued for K.'s study: it provides its reader with an instructive display, not just a peek, of a philologist's workshop. Its major default, however, lies at the very articulation of that display: despite his introductory explanation for his choice, still his decision to publish his work in Greek, although it does corroborate the high standards of Greek clas- 
sicists, unfortunately it also limits its accessibility to young classicists abroad and/or to a broader classics readership. Thus, K.'s work recalls its subject, though in reverse and perhaps ironically: classical studies should aspire to the translation of his Aкi $\chi \alpha \rho o \varsigma$ at least into the new dominant language of a wider oikoumene. 